\title{
A QUASI EXPERIMENTAL STUDY TO ASSESS THE EFFECTIVENESS OF NURSING INTERVENTION ON ENHANCING SELF MOTIVATION TO MAINTAIN ABSTINENCE IN ALCOHOL DEPENDENT ADULTS \\ Mr. Keshav Kumar Vashishth* | Dr. Rajendra Prasad Sharma* \\ *Associate Professor, Mahatma Gandhi Nursing College, Sitapur, Jaipur, India. DOI: http://doi.org/10.47211/trr.2019.v05i02.002 \\ Received $5^{\text {th }}$ October 2019, Accepted $5^{\text {th }}$ December 2019, Published $20^{\text {th }}$ December 2019
}

\begin{abstract}
Alcohol has been discovered and used by practically every culture in the world. This practice has invariably produced problems of alcohol misuse. Edwards and Gross introduced the concept of alcohol dependence syndrome as a cluster of core psycho-physiological symptoms principally centred around a drive to consume alcohol. Among the reasons for this may be such things as a highly skewed distribution of drinkers in the society, the prevalence of nutritional and infectious diseases, economic deprivation, more hazardous and accident-prone physical environments, and lack of any organised support system. Although conclusive scientific evidence for alcohol related health and social problems is lacking for India, there are enough indications in the available literature to infer that these are substantial. Women's 'sanghas' participating in a women health empowerment training in several districts in Karnataka have consistently said that the biggest problem they face relate to alcohol abuse. Community health groups in different parts of the country also recognise the importance of the problem. The rapid rise in alcohol consumption in recent years has increased the likelihood of further growth of the health problems in the years to come.The concept had a tremendous influence in the field of alcohol studies it was included by the world health organisation as one of the components of alcohol related disabilities. The study concludes that all the alcohol dependent adult males have some level of motivation to maintain abstinence from alcohol. This level of motivation can be enhanced by using nursing interventional techniques to maintain long term abstinence.
\end{abstract}

Keywords: Alcohol dependent adults, Self-Motivation, abstinence. 


\section{ARTICLES}

\section{INTRODUCTION AND BACKGROUND}

The alcohol dependence syndrome is considered as process, distinct from other alcohol related problems such as social, legal, work or health problems and this was accepted by all international classification systems.

Although alcohol consumption has existed in India for many centuries, the quality patterns of use and resultant problems have undergone substantial changes over the past two decades. Alcohol consumption produces individual health and social problems. The global burden of disease from alcohol exceeds that of tobacco and is on a par with the burden attributable to unsafe sex worldwide.

Although recorded alcohol consumption per capita has fallen since 1980 in most developed countries, it has risen steadily in developing countries and alarmingly so in India. The per capita consumption of alcohol by adults of 15 years and above in India increased by 106.67 percent between 1970-72 and 1994-96. It is probable, given equal amounts of drinking, that developing countries like India experience more problems than developed countries do.

According to WHO report, Indians consumed 2.4 litre of alcohol in 2005, which increased to 4.3 litres in 2010 and scaled up to 5.7 litres in 2016.

\section{OBJECTIVES OF THE STUDY}

1. To assess the pre-intervention level of motivation in maintaining abstinence from alcohol among the adult clients.

2. To provide nursing intervention in the form of "Self-motivation package to maintain abstinence from alcohol" in the adult clients.

3. To assess the post interventional level of motivation in maintaining abstinence from alcohol among the adult clients.

4. To associate the level of motivation with selected socio-demographic variables.

\section{HYPOTHESIS}

H1: Enhancing self-motivation facilitates self-control to maintain abstinence from alcohol.

\section{ASSUMPTIONS}

Alcohol dependents who seek help to maintain abstinence from alcohol consumption will have some motivation.

\section{EXCLUSION CRITERIA}

Adult alcohol dependants suffering from any other serious physical or mental disorders are excluded from the study.

\section{DEVELOPMENT OF INFORMATION BOOKLET}

Information booklet was prepared on the basis of review of literature and expert opinion. The information booklet was titled as "Everything about alcohol" and organised into various headings:

- Introduction to Alcohol

- Importance of Alcoholic Problem

- Alcoholic Beverages

- Standard Drinks and Intoxication

- Myths and facts about Alcohol

- Effects of Alcohol, Short Term and Long Term

- Abstinence from alcohol

- Motivation techniques

- Conclusion 


\section{ARTICLES}

\section{RESULTS}

The findings are presented in three sections -

- Section I: Socio-demographic characteristics of alcohol dependent adult

- Section II: Analysis of the effectiveness of self motivation package

- Section III: Association of self motivation with selected demographic variables.

This section deals with the knowledge score of your subject regarding Nursing Intervention on Enhancing SelfMotivation to Maintain Abstinence in Alcohol Dependent Adults.

It has also been analysed in terms of frequency and percentage.

\section{Table - 2.1}

Scores and responses of participants on the level of knowledge regarding Nursing Intervention on Enhancing SelfMotivation to Maintain Abstinence in Alcohol Dependent Adults.

\begin{tabular}{|l|c|c|}
\hline & \multicolumn{2}{|c|}{ Pre-test } \\
\hline Level of knowledge & Frequency (f) & Percentage (\%) \\
\hline Low Motivated & 27 & 22.0 \\
\hline Moderately Motivated & 11 & 24.0 \\
\hline Highly Motivated & 12 & 100.0 \\
\hline Total & 50 & \\
\hline
\end{tabular}

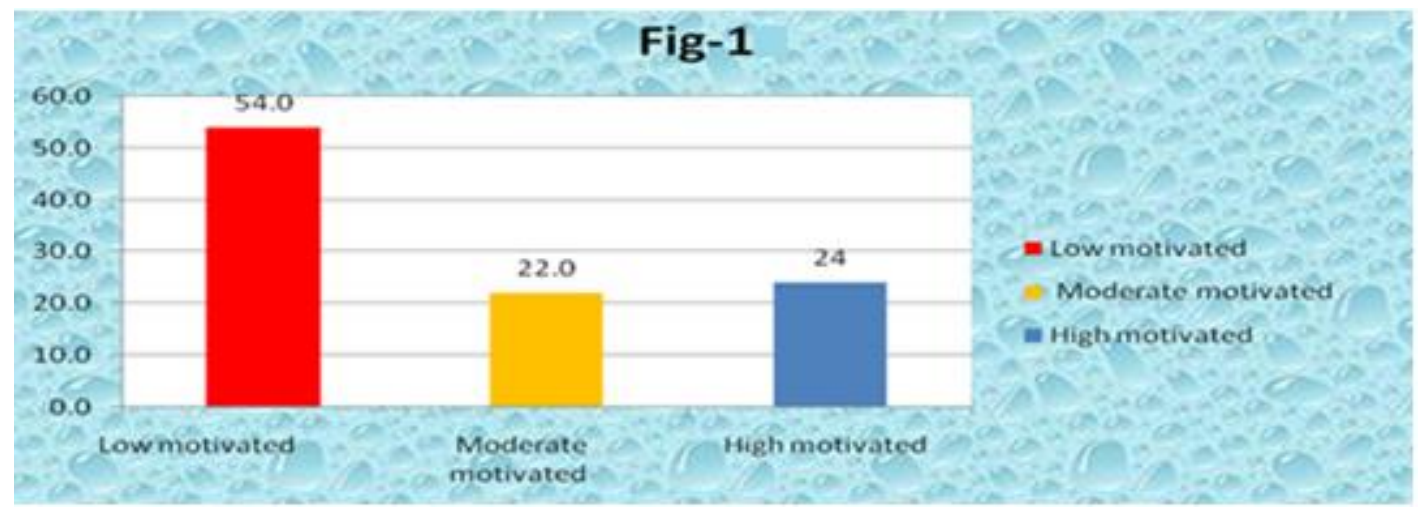

Fig. 1: Bar diagram shows the pre-test of knowledge of subjects regarding Nursing Intervention on Enhancing SelfMotivation to Maintain Abstinence in Alcohol Dependent Adults.

\section{Pre-test}

\begin{tabular}{|c|c|c|c|c|}
\hline Valid & Frequency & Percent & Valid Percent & Cumulative Percent \\
\hline 1. & 27 & 54.0 & 54.0 & 54.0 \\
\hline 2. & 11 & 22.0 & 22.0 & 76.0 \\
\hline 3. & 12 & 24.0 & 24.0 & 100.0 \\
\hline Total & 50 & 100.0 & 100.0 & \\
\hline
\end{tabular}




\section{ARTICLES}

Table - 2.2:

Scores and responses of participants on the Post-test knowledge regarding Nursing Intervention on Enhancing SelfMotivation to Maintain Abstinence in Alcohol Dependent Adults

\begin{tabular}{|l|c|c|}
\hline & \multicolumn{2}{|c|}{ Post-test } \\
\hline Level of knowledge & Frequency (f) & Percentage (\%) \\
\hline Low Motivated & 17 & 16.0 \\
\hline Moderately Motivated & 8 & 50.0 \\
\hline Highly Motivated & 25 & 100.0 \\
\hline Total & 50 & \\
\hline
\end{tabular}

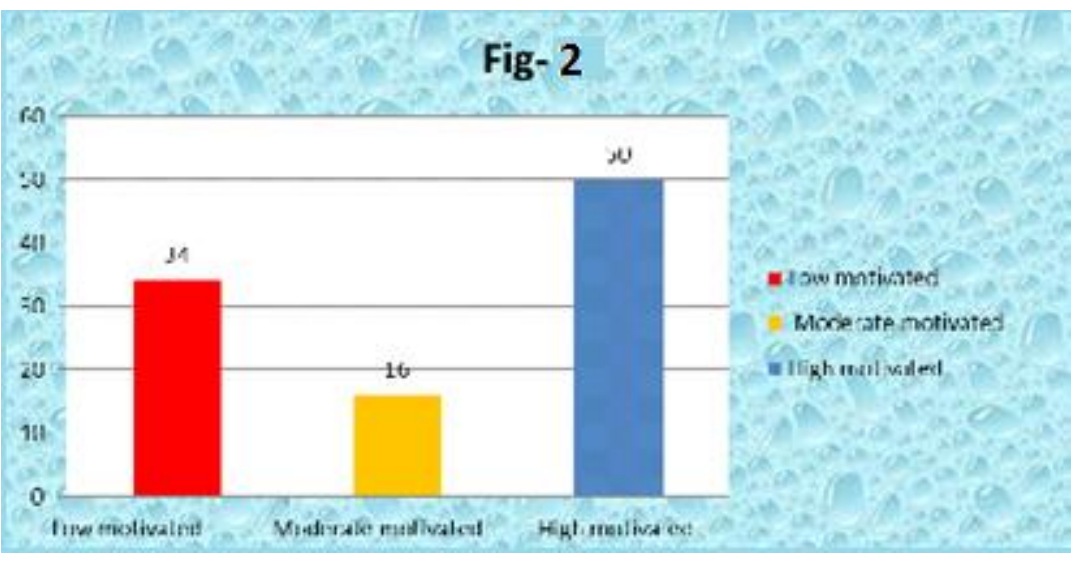

Fig. 2- Bar diagram shows the post-test knowledge regarding Nursing Intervention on Enhancing Self-Motivation to Maintain Abstinence in Alcohol Dependent Adults.

Post-test

\begin{tabular}{|c|c|c|c|c|}
\hline Valid & Frequency & Percent & Valid Percent & Cumulative Percent \\
\hline 1. & 17 & 34.0 & 34.0 & 34.0 \\
\hline 2. & 8 & 16.0 & 16.0 & 50.0 \\
\hline 3. & 25 & 50.0 & 50.0 & 100.0 \\
\hline Total & 50 & 100.0 & 100.0 & \\
\hline
\end{tabular}

Table - 2.3:

\begin{tabular}{|l|c|c|c|c|}
\hline & & Mean X & & \\
\hline Motivation & Scores & Mean X & Std. Deviation & Mean Percentage \\
\hline Motivation & 150.00 & 80.58 & 20.658 & 53.720 \\
\hline About problems & 65.00 & 36.26 & 13.302 & 55.780 \\
\hline Knowledge & 85.00 & 44.32 & 14.256 & 52.140 \\
\hline
\end{tabular}

The above table 2.3 (mean X) shows summary of statistical outcomes of Nursing Intervention on Enhancing SelfMotivation to Maintain Abstinence in Alcohol Dependent Adults In overall maximum knowledge Score Alcohol Dependent Adults on prevention of Alcohol Dependent Adults. Maximum score were 150. The mean score was 80.58 with standard deviation 20.658. The mean score percentage was computed and it was found to be $53.720 \%$. 


\section{ARTICLES}

The above table 2.3(mean X) shows summary of statistical outcomes of Nursing Intervention On Enhancing SelfMotivation To Maintain Abstinence In Alcohol Dependent Adults In About problems maximum knowledge Score Alcohol Dependent Adults on prevention of Alcohol Dependent Adults. Maximum score were 65. The mean score was 36.26 with standard deviation 13.302. The mean score percentage was computed and it was found to be $55.780 \%$.

The above table 2.3(mean X) shows summary of statistical outcomes of Nursing Intervention on Enhancing SelfMotivation to Maintain Abstinence in Alcohol Dependent Adults. In Knowledge regarding maximum knowledge Score Alcohol Dependent Adults on prevention of Alcohol Dependent Adults. Maximum score were 85. The mean score was 44.32 with standard deviation 14.256. The mean score percentage was computed and it was found to be $52.140 \%$.

Table-2.3 (a):

\begin{tabular}{|l|c|c|c|c|}
\hline & & Mean Y & & \\
\hline Motivation & Scores & Mean Y & Std. Deviation & Mean Percentage \\
\hline Motivation & 150.00 & 129.66 & 16.201 & 86.440 \\
\hline About problems & 65.00 & 56.84 & 7.327 & 87.440 \\
\hline Knowledge & 85.00 & 72.82 & 10.388 & 85.670 \\
\hline
\end{tabular}

The above table 2.3 a (mean Y) shows summary of statistical outcomes of Nursing Intervention on Enhancing SelfMotivation to Maintain Abstinence in Alcohol Dependent Adults In overall maximum knowledge Score Alcohol Dependent Adults on prevention of Alcohol Dependent Adults. Maximum score were 150. The mean score was 129.66 with standard deviation 16.201 . The mean score percentage was computed and it was found to be $86.440 \%$.

The above table 2.3 a (mean YX) shows summary of statistical outcomes of Nursing Intervention on Enhancing SelfMotivation to Maintain Abstinence in Alcohol Dependent Adults in About problems maximum knowledge Score Alcohol Dependent Adults on prevention of Alcohol Dependent Adults. Maximum score were 65. The mean score was 56.84 with standard deviation 7.327. The mean score percentage was computed and it was found to be $87.44 \%$. The above table $2.3 \mathrm{a}$ (mean $\mathrm{Y}$ ) shows summary of statistical outcomes of Nursing Intervention On Enhancing SelfMotivation To Maintain Abstinence In Alcohol Dependent Adults In Knowledge regarding maximum knowledge Score Alcohol Dependent Adults on prevention of Alcohol Dependent Adults. Maximum score were 85. The mean score was 72.82 with standard deviation 10.388 . The mean score percentage was computed and it was found to be $85.670 \%$.

Table - 2.3 (b):

\begin{tabular}{|l|c|c|c|c|}
\hline & & $(\mathbf{Y}-\mathbf{X})$ & & \\
\hline Motivation & Scores & $\mathbf{M}$ & Std. Deviation & Mean Percentage \\
\hline Motivation & 150.00 & -49.080 & 27.497 & 32.720 \\
\hline About problems & 65.00 & -20.580 & 14.333 & 30.600 \\
\hline Knowledge & 85.00 & -28.500 & 18.543 & 35.530 \\
\hline
\end{tabular}

The above table 2.3(b) shows summary of statistical outcomes of Nursing Intervention on Enhancing Self-Motivation to Maintain Abstinence in Alcohol Dependent Adults In overall maximum knowledge Score Alcohol Dependent Adults on prevention of Alcohol Dependent Adults. Maximum score were 150. The mean score was 49.080 with standard deviation 27.497. The mean score percentage was computed and it was found to be $32.720 \%$. 


\section{ARTICLES}

The above table 2.3(effectiveness) shows summary of statistical outcomes of Nursing Intervention on Enhancing SelfMotivation to Maintain Abstinence in Alcohol Dependent Adults in About problems maximum knowledge Score Alcohol Dependent Adults on prevention of Alcohol Dependent Adults. Maximum score were 65. The mean score was 20.580 with standard deviation 14.333. The mean score percentage was computed and it was found to be $30.600 \%$.

The above table 2.3(effectiveness) shows summary of statistical outcomes of Nursing Intervention on Enhancing SelfMotivation to Maintain Abstinence in Alcohol Dependent Adults in Knowledge regarding maximum knowledge Score Alcohol Dependent Adults on prevention of Alcohol Dependent Adults. Maximum score were 85. The mean score was 28.500 with standard deviation 18.543. The mean score percentage was computed and it was found to be $35.530 \%$.

Table - $2.3(\mathrm{C})$ :

\begin{tabular}{|l|c|c|c|c|c|c|c|c|c|c|}
\hline Motivation & scores & Mean & S.D & Mean \% & Mean Y & S.D & Mean \% & M & S.D & Mean \% \\
\hline Motivation & 150.00 & 80.58 & 20.658 & 53.720 & 129.66 & 16.201 & 86.440 & -49.080 & 27.497 & 32.720 \\
\hline $\begin{array}{l}\text { About } \\
\text { problems }\end{array}$ & 65.00 & 36.26 & 13.302 & 55.780 & 56.84 & 7.327 & 87.440 & -20.580 & 14.333 & 30.600 \\
\hline $\begin{array}{l}\text { Knowledge } \\
\text { regarding }\end{array}$ & 85.00 & 44.32 & 14.256 & 52.140 & 72.82 & 10.388 & 85.670 & -28.500 & 18.543 & 35.530 \\
\hline
\end{tabular}

Table - 2.4:

Comparison of pre- and post-test groups on knowledge mean about Nursing Intervention on Enhancing SelfMotivation to Maintain Abstinence in Alcohol Dependent Adults.

\begin{tabular}{|l|l|c|c|c|c|c|}
\hline & & Mean & Std. Deviation & M & t-test & Results of H0 \\
\hline \multirow{3}{*}{ Motivation } & Pre & 80.58 & 20.658 & 49.080 & 12.621 & \\
\cline { 2 - 7 } & Post & 129.66 & 16.201 & & & \\
\hline \multirow{3}{*}{ About problems } & Pre & 36.26 & 13.302 & 20.580 & 10.153 & \\
\cline { 2 - 7 } & Post & 56.84 & 7.327 & & & 10.868 \\
\hline
\end{tabular}

According to table No. 2.4, which indicates that mean \& S.D of Motivation in Pre vs Post-test on knowledge about Nursing Intervention on Enhancing Self-Motivation to Maintain Abstinence in Alcohol Dependent Adults i.e. pre-test group are $80.58 \pm 20.658$, post-test are $129.66 \pm 16.201$. As per the table the mean difference of pre vs post-test group was 49.080 and the t-ratio were statistically significant as the obtained value (12.621) was higher than the tabulated value (2.00) required for t-ratio to be significant at 0.05 level of confidence.

About problems: here in pre-test group the mean and S.D of knowledge are $36.26 \pm 13.302$, in post-test they are $56.84 \pm 7.327$. As per the table the mean difference of pre- vs post-test group of Adolescent Girls in a rural area School in Jaipur was 20.580 and the t-ratio was statistically significant as the obtained value (10.153) was higher than the tabulated value (2.00) required for t-ratio to be significant at 0.05 level of confidence.

Knowledge regarding: here in pre-test group the mean and S.D of knowledge are $44.32 \pm 14.256$, in post-test they are 72.82 \pm 10.388 . As per the table the mean difference of pre- vs post-test group was 28.500 and the t-ratio was 


\section{ARTICLES}

statistically significant as the obtained value (10.868) was higher than the tabulated value (2.00) required for t-ratio to be significant at 0.05 level of confidence

\section{CONCLUSION}

The study concludes that all the alcohol dependent adult males have some level of motivation to maintain abstinence from alcohol. This level of motivation can be enhanced by using nursing interventional techniques to maintain long term abstinence.

\section{REFERENCES}

1. Mallika S. An assessment of motivation among relapsed and abstinent alcohol dependent individuals. Unpublished MSc. Nsg. Dissertation, NIMHANS, Bangalore. 1997; 21-46.

2. Midanik, Goldman HH. Review of general psychiatry 4th ed prentice-hall international Inc; 1995:203.

3. King MP, Tucker JA Natural resolution of alcohol problems without treatment. Addictive behaviour; 1991:53741.

4. Kuruvilla K, The prevention of alcohol related problems. Indian Journal of psychiatry; 33(1): 3-10.

5. Kothari CR. Research methodology - methods and techniques. New Delhi, Viswa Prakasan Publishers, 1996:187.

6. Declemente, C.C, and Hughes, S.O stages of change profiles in alcoholism treatment, Journal of substance abuse, 1990; 2:217-235. 